\title{
Production of lactic acid from cellulose using solid catalyst
}

\author{
Sujitra Doungsri ${ }^{1}, P$. Rattanaphanee ${ }^{1}$ and Aatichat Wongkoblap ${ }^{1, *}$ \\ ${ }^{1}$ School of Chemical Engineering, Institute of Engineering, Suranaree University of Technology, Nakhon Ratchasima 30000, Thailand
}

\begin{abstract}
Lactic acid (LA), one of the important biomass derived platform chemicals, has been used in food and chemical industries, especially in biodegradable polymer as polylactic acid (PLA). The aim of this work is to study the one-pot production of LA from cellulose by using different solid catalysts. The reaction was conducted in a high pressure batch reactor and the catalyst used in this study were $\mathrm{ZrO}_{2}$ and $\mathrm{Al}_{2} \mathrm{O}_{3}$. The reaction was carried out at temperature of $200^{\circ} \mathrm{C}$ for $6 \mathrm{hr}$. and under nitrogen pressure of $1 \mathrm{MP}$. It was found that the production yield of LA were $8.02 \%$ and $6.63 \%$, when the $\mathrm{ZrO}_{2}$ and $\mathrm{Al}_{2} \mathrm{O}_{3}$ catalysts were used respectively. The result indicated that the $\mathrm{ZrO}_{2}$ may effect on the LA production because of the acid and base sites of the $\mathrm{ZrO}_{2}$. Therefore, the reaction pathways for conversion of cellulose into lactic acid have been investigated, and developed the new conditions to achieve the higher yield.
\end{abstract}

\section{Introduction}

Not only facing the environmental problems but also the restricted available resources of fossil fuels, has served as a driving force to develop new strategies for using non-fossil, clean, and long term alternative fuels. Biomass has become one of the energy resources as a replacement for fossil fuels because its benefit is the most abundant green renewable resource. Cellulose, as the most abundant, non-food, and renewable organic compound, has been considered as a potential alternative feedstock to reduce fossil fuel consumption [1-2].

Lactic acid (LA) is one of important carboxylic acid that can be produced from biomass, and has several applications such as food, pharmaceutical and chemical industries. One of the important application of lactic acid is biodegradable polymer as polylactic acid (PLA). Even though most of lactic acid is commercially produced by the microbial fermentation of aqueous glucose, several chemical processes to synthesis lactic acid from petrochemical resources are still challenged [3-4]. However, biological processes have various drawbacks such as high cost of culture media, low reaction rates causing long reaction times and huge reactors required, and low concentrations of products requiring high energy consumption for purification. As a result, these will lead to high production cost of the lactic acid. In addition, biological processes are quite sensitive to $\mathrm{pH}$ and temperature parameters [5-6].

Cellulose can be converted to lactic acid via hydrothermal process in a presence of catalyst as shown in Fig. 1 proposed by Yamaguchi et. al. [7]. First, cellulose is hydrolyzed and converted into glucose, and then the second step, the isomerization of glucose to fructose, using bases or Lewis acids catalysts occurs. Third, the fructose is converted into glyceraldehyde and 1,3-dihydroxyacetone through Retro-aldol reaction. Next, dehydration of glyceraldehyde (GLA) and 1,3-

\footnotetext{
* Corresponding author: atichat@sut.ac.th
}

dihydroxyacetone (DHA) are occurred and converted into pyruvaldehyde. Finally, pyruvaldehyde is reacted with methanol and converted into lactic acid. Many researchers have been used homogeneous catalytic processes using alkaline and alkaline-earth metal catalysts which yielded high amount of lactic acid. However, the separation of catalyst from product solution is quite difficult. The heterogeneous catalysis for the conversion of cellulose has been expected to overcome this issue. Various types of heterogeneous catalysts can be designed and applied in a wide range of reaction conditions. Furthermore, solid catalysts are easily recovered and reused [2].

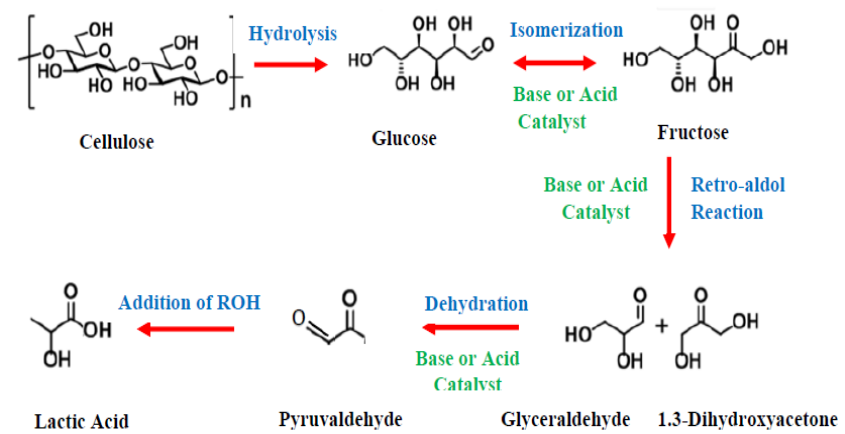

Figure 1. Reaction Pathway for the Conversion of Cellulose into Lactic Acid [7].

The aim of this work is to study the one-pot production of LA from cellulose by using different solid catalysts. The reaction was conducted in a high pressure batch reactor and the catalysts used in this study were $\mathrm{ZrO}_{2}$ and $\mathrm{Al}_{2} \mathrm{O}_{3}$. 


\section{Materials and methods}

\subsection{Materials and reagents}

Aluminum oxide $\left(\mathrm{Al}_{2} \mathrm{O}_{3}\right.$, Sigma-Aldrich), Zirconium oxide $\left(\mathrm{ZrO}_{2}\right.$, Wako) were used as solid catalysts in this study. The analytical grade reagent of DL-lactic acid $(\geq 85 \%)$, formic acid $(\geq 95 \%)$, acetic acid $(\geq 99.7 \%)$ levulinic acid $(\geq 95 \%)$, propionic acid $(\geq 95 \%)$ and hydroxymethylfurfural (HMF) ( $\geq 95 \%$ ) were used for HPLC standards and obtained from Sigma-Aldrich. Cellulose from cotton linter obtained from Nitrochemical Industry Ltd, ( $>99 \%$ ) was used as feedstock.

All experiments were conducted in a $100 \mathrm{~mL}$ stainless steel batch reactor with an internal diameter of 2.0 inches and an internal depth of 2.0 inches. The schematic diagram of the reactor and the reactor (supplied by Ann Parr) used in this study were shown in Fig. 2 and 3, respectively.

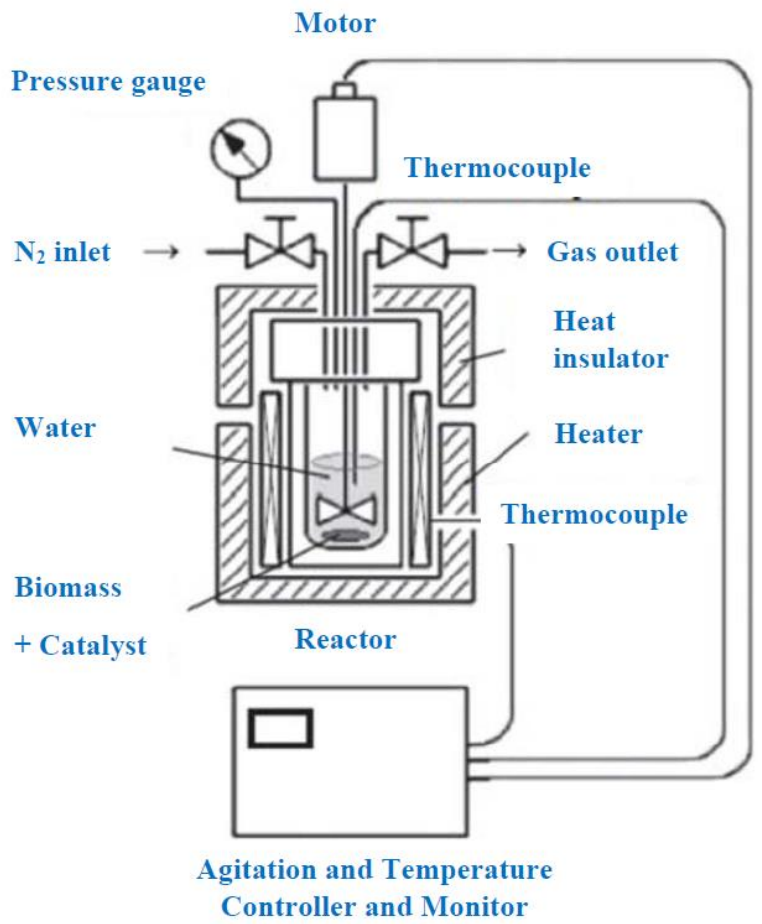

Figure 2. Schematic reaction apparatus [8].

\subsection{Experimental set-up and procedure}

\subsubsection{Liquefaction reaction}

The amount of catalyst $(1 \mathrm{~g})$, deionized water $(50 \mathrm{~g})$, and cellulose $(0.5 \mathrm{~g})$ were put into a high pressure batch reactor with an agitation speed of $400 \mathrm{rpm}$, as shown in Fig. 2. Then, the vessel was rapidly heated to temperature of $200{ }^{\circ} \mathrm{C}$ and was kept at this temperature for $360 \mathrm{~min}$, which was the nominal reaction time, under a gaseous nitrogen atmosphere with an initial pressure of $1 \mathrm{MPa}$. The pressure after having reached the reaction temperature was about $10.0 \mathrm{MPa}$. The reaction was stopped by cooling the vessel in an ice water trap. After the reaction, the liquid products were separated from the

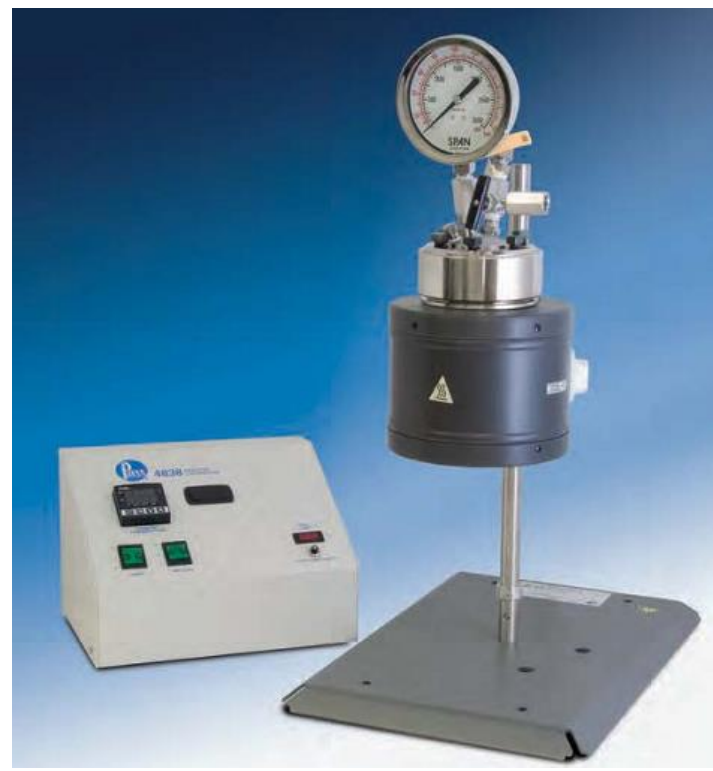

Figure 3. Reactor and accessories used in this study (supplied by Ann Parr)

mixture via filtration using a membrane filter $(0.2 \mu \mathrm{m}$; Sartorius Stedim Biotech SA, Germany).The mixture of the unreacted cellulose and the catalyst was washed with distilled water. The unreacted cellulose was recovered from the suspension solution because the catalyst has a bigger density. Then, the unreacted cellulose, and the catalyst were dried to a constant weight at $105^{\circ} \mathrm{C}$ in an oven, respectively.

\subsubsection{Analysis}

The LA yield and conversion of cellulose defined as the percentage are given in Eqs. 1 and 2.

$$
\operatorname{Yield}(\%)=\left(\frac{W_{L A}}{W_{\text {initial }}}\right) x 100 \%
$$

$$
\text { Conversion, }(\%)=\left(1-\frac{W_{\text {unreacted }}}{W_{\text {initial }}}\right) \times 100 \%
$$

where $W_{\text {initial }}=$ weight of initial cellulose $(\mathrm{g}), W_{\mathrm{LA}}=$ weight of LA $(\mathrm{g}), W_{\text {unreacted }}=$ weight of unreacted cellulose $(\mathrm{g})$.

After reaction, liquid samples were filtered through $0.2 \mu \mathrm{m}$ syringe and then analyzed by high performance liquid chromatography (HPLC, Agilent Technologies 1260). The HPLC system was equipped with a UV/vis absorbanc detector and Biorad Aminex HPX-87H $300 \mathrm{x}$ $7.8 \mathrm{~mm}$ organic acid column, using $5 \mathrm{mM} \mathrm{H}_{2} \mathrm{SO}_{4}$ as the mobile phase diluted with demineralized water set at a flow rate of $0.5 \mathrm{~mL} / \mathrm{min}$. The column temperature was $40^{\circ} \mathrm{C}$ and the detector was set to $40^{\circ} \mathrm{C}$. Each sample ran for $60 \mathrm{~min}$. The products were determined by comparing 
with standard solutions prepared by dissolving the commercial acids in demineralized water.

\section{Results and discussion}

\subsection{Effect of catalyst on formation of lactic acid}

The catalytic conversion of cellulose using 2 metal oxides $\left(\mathrm{Al}_{2} \mathrm{O}_{3}\right.$ and $\left.\mathrm{ZrO}_{2}\right)$ as solid catalysts and using hydrothermal conversion without solid catalysts as a reference are summarized in Table 1 and Fig. 4. In this study, we used cellulose after size distribution by using screening bag (size $1 \mathrm{~mm}$ ) to decrease the crystallinity of cellulose and increase the cellulose hydrolysis [11-12]. Without solid catalysts, only $0.7 \%$ yield of lactic acid could be obtained. The results of using solid catalysts found that the production yield of LA were $8.02 \%$ and $6.63 \%$, when the $\mathrm{ZrO}_{2}$ and $\mathrm{Al}_{2} \mathrm{O}_{3}$ catalysts were used respectively. The result indicated that the $\mathrm{ZrO}_{2}$ may effect on the LA production than $\mathrm{Al}_{2} \mathrm{O}_{3}$ catalyst.
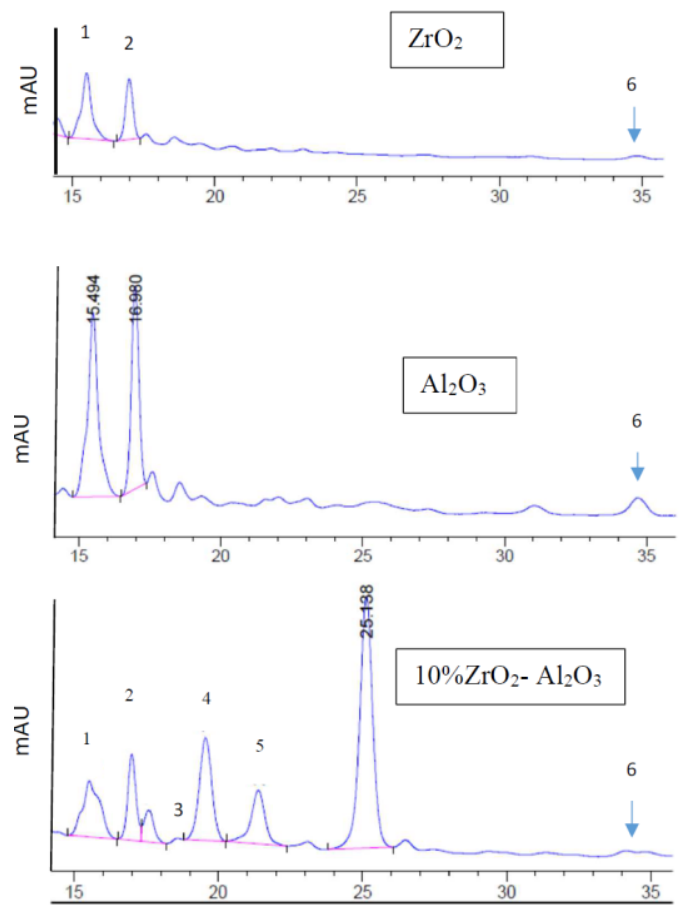

Retention Time (min)

Figure 4. HPLC Chromatogram for LA Production (1; lactic acid, 2; Formic acid, 3; Acetic acid, 4 Levulinic acid, 5; Propionic acid and 6; Hydroxymethylfurfural (HMF).

Table 1. Acid and Base Properties of Metal Oxide Catalysts.

\begin{tabular}{lcccc}
\hline Catalyst & $\begin{array}{c}\text { BET } \\
\text { surface } \\
\text { Area } \\
{\left[\mathrm{m}^{2} / \mathrm{g}\right]}\end{array}$ & $\begin{array}{c}\text { Amount } \\
\text { of Acid } \\
\text { Sites } \\
{[\mathrm{mmol} / \mathrm{g}]}\end{array}$ & $\begin{array}{c}\text { Amount } \\
\text { of Base } \\
\text { Sites } \\
{[\mathrm{mmol} / \mathrm{g}]}\end{array}$ & $\begin{array}{c}\text { Lactic } \\
\text { Acid } \\
\text { Yield } \\
{[\%]}\end{array}$ \\
\hline $\mathrm{Al}_{2} \mathrm{O}_{3}$ & $151^{\mathrm{a}}$ & $0.160^{\mathrm{a}}$ & $0.400^{\mathrm{a}}$ & 6.63 \\
$\mathrm{ZrO}_{2}$ & $18.6^{\mathrm{b}}$ & $0.033^{\mathrm{b}}$ & $0.039^{\mathrm{b}}$ & 8.02 \\
$10 \% \mathrm{ZrO}_{2}-$ & 117.1 & $0.131^{\mathrm{b}}$ & $0.057^{\mathrm{b}}$ & 11.44 \\
$\mathrm{Al}_{2} \mathrm{O}_{3}$ & & & & \\
\hline
\end{tabular}

${ }^{\mathrm{a}}$ Data from ref.[9], ${ }^{\mathrm{b}}$ data from ref. [10].

The effect of catalyst on formation of lactic acid is mostly due to the amount of acid sites and base sites of metal oxides which can be analysed by $\mathrm{NH}_{3}$-TPD and
$\mathrm{CO}_{2}$-TPD, respectively [13-15]. These amounts are shown in Table 1, as one can see from the table, the BET area, the amount of acid and base sites of $\mathrm{Al}_{2} \mathrm{O}_{3}$ are greater than those of $\mathrm{ZrO}_{2}$. However, if we consider the surface concentration of acid and base sites on catalyst, it is found that the acid site surface concentration of $\mathrm{ZrO}_{2}$ $\left(0.001774 \mathrm{mmol} / \mathrm{m}^{2}\right)$ is greater than those of $\mathrm{Al}_{2} \mathrm{O}_{3}$ $\left(0.001059 \mathrm{mmol} / \mathrm{m}^{2}\right)$ while the opposite is true for the surface concentration of base sites. Molecules of fructose are initially adsorbed at acid sites and then converted into GLA and DHA, therefore the greater surface concentration of acid sites may lead to the greater conversion of LA. The detail mechanism will be discussed in the next section.

\subsection{Mechanism studies for lactic acid production}

According to comparing the performance of catalysts, the reaction pathways for conversion of cellulose into lactic acid have investigated. The degradation pathway of polysaccharides such as cellulose is shown in Fig. 1. Initially, cleavage of the glycosidic linkage in all polysaccharides leads to the production of a common main component, namely the glucose monomer. It has been reported that glucose and its isomer fructose are decomposed to give trioses (C3), including 1,3dihydroxyacetone (DHA) and glyceraldehyde (GLA) by a retro-aldol reaction [16-17] and the formation of LA derivative via dehydration and subsequent 1,2-hydride shift [18-22].

From the details of the reaction pathways, the key step for LA production is fructose into GLA and DHA by a retro-aldol reaction involving $\mathrm{C}-\mathrm{C}$ bond cleavage, which is reported to be enhanced by Lewis acid [23-25]. The proposed mechanism for fructose conversion into GLA and DHA by a retro-aldol reaction on acid ( $\mathrm{Zr}$ is Lewis acid) and base sites $(\mathrm{Zr}-\mathrm{OH})$ of $\mathrm{ZrO}_{2}$ is shown in Fig. 5. The carbonyl group of the fructose interacts with the $\mathrm{Zr}$ site of the Lewis acid, and in the same time the $\mathrm{OH}$ group at the position of the C-4 carbon also adsorbs onto the oxygen atom of the base site. The cleavage of $\mathrm{C}-\mathrm{C}$ bond between $\mathrm{C}-3$ and $\mathrm{C}-4$ of fructose leads to the formation of GLA and DHA. The dehydration of GLA and DHA into pyruvaldehyde is occurred and then pyruvaldehyde is reacted with alcohol and converted into LA at Lewis acid sites of catalyst as showed in Fig. 6. Hisakazu et al. reported in the literature [26] that the Bronsted acid catalyst which lone pair electrons of $\mathrm{O}$ site contact with $\mathrm{H}$, favors the formation of hydroxymethylfurfural (HMF) by dehydration reaction.

The yield of LA from $\mathrm{ZrO}_{2}$ catalyst is greater than that of $\mathrm{LA}$ from $\mathrm{Al}_{2} \mathrm{O}_{3}$ catalyst. As discussed in the previous section, LA production depends on the surface concentration of Lewis acid site, and the other reason may be due to the surface concentration of base site $(\mathrm{O}$ site). The base site concentration of $\mathrm{Al}_{2} \mathrm{O}_{3}$ is greater than that of $\mathrm{ZrO}_{2}$ and this leads to the greater amount of $\mathrm{HMF}$ which is the side reaction of fructose conversion, as seen from chromatogram in Figure 4. 


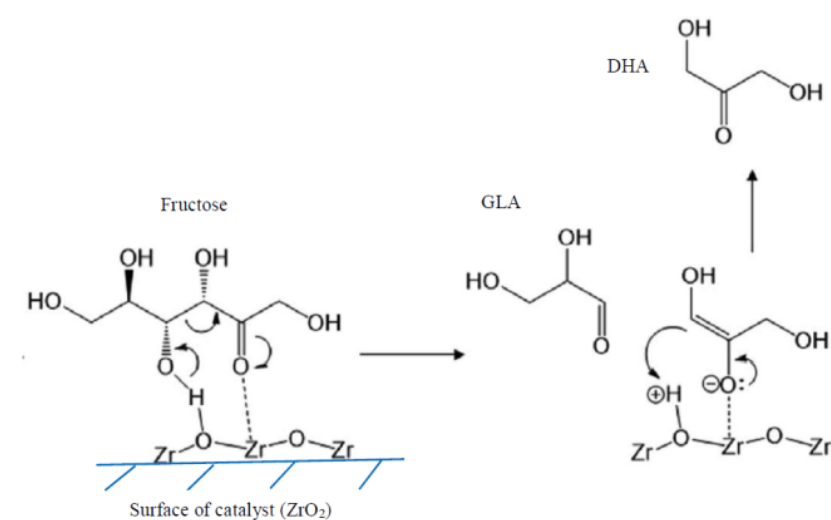

Figure 5. Proposed mechanism for fructose conversion into glyceraldehyde (GLA) and dihydroxyacetone (DHA) by a retro-aldol reaction on acid and base sites of $\mathrm{ZrO}_{2}$. Figure 5 was modified from [10].

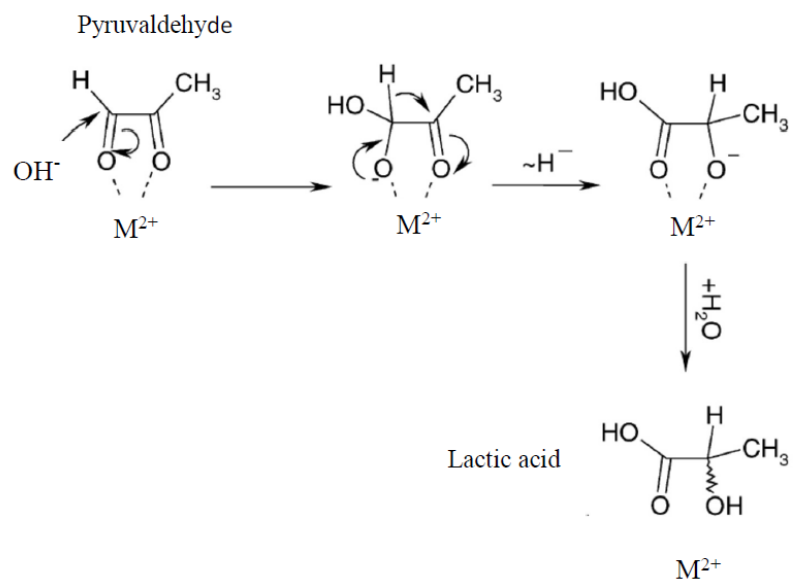

Figure 6. Proposed mechanism for pyruvaldehyde conversion into lactic acid on metal ion $\left(\mathrm{M}^{2+}\right)$. Figure 6 was modified from [27].

Wattanapaphawong et al. [10] investigated the catalytic conversion of cellulose to lactic acid by using various transition metal oxides (i.e., $\mathrm{ZrO}_{2}, \mathrm{Al}_{2} \mathrm{O}_{3}, \mathrm{TiO}_{2}$, $\mathrm{Fe}_{3} \mathrm{O}_{4}, \mathrm{~V}_{2} \mathrm{O}_{5}, \mathrm{CeO}_{2}, \mathrm{Y}_{2} \mathrm{O}_{3}, \mathrm{Tm}_{2} \mathrm{O}_{3}, \mathrm{HfO}_{2}, \mathrm{Ga}_{2} \mathrm{O}_{3}, \mathrm{MgO}$, $\mathrm{La}_{2} \mathrm{O}_{3}, \mathrm{Nb}_{2} \mathrm{O}_{5}$, and $\mathrm{Ta}_{2} \mathrm{O}_{5}$ ), they have found that of these catalysts, $\mathrm{ZrO}_{2}$ had the highest catalytic activity (reaction temperature, $473 \mathrm{~K}$ ). Therefore, in this work, we mixed $10 \%$ of $\mathrm{ZrO}_{2}$ with $\mathrm{Al}_{2} \mathrm{O}_{3}$ to investigate the possibility to developing the new catalysts and conditions to achieve the higher yield. The yield of $10 \%$ of $\mathrm{ZrO}_{2}-\mathrm{Al}_{2} \mathrm{O}_{3}$ catalyst was $11.44 \%$, which higher than the yield of $\mathrm{ZrO}_{2}$ and $\mathrm{Al}_{2} \mathrm{O}_{3}$ catalysts respectively. However, mixing $10 \%$ of $\mathrm{ZrO}_{2}$ with $90 \%$ of $\mathrm{Al}_{2} \mathrm{O}$ can increase some organic acids such as formic acid, acetic acid, Levulinic acid and Propionic acid, this may be due to the decomposition of lactic acid from side reaction. It is noted that while the yield of LA increased, the amount of HMF decreased as observed in the chromatogram. This may be due to the surface concentration of base sites of mixed catalyst decreased.

This suggests that dispersion of $\mathrm{ZrO}_{2}$ on $\mathrm{Al}_{2} \mathrm{O}_{3}$ support and accessibility to the acid sites and base sites on the catalyst are the most important factors for the conversion of cellulose to lactic acid when using $\mathrm{ZrO}_{2}-$
$\mathrm{Al}_{2} \mathrm{O}_{3}$ catalysts. Further studies are required to elucidate the details of the relationship between the active sites and the product yield and also the reaction mechanism.

\section{Conclusion}

In this study, $\mathrm{ZrO}_{2}, \mathrm{Al}_{2} \mathrm{O}_{3}$ and mixed $\mathrm{ZrO}_{2}-\mathrm{Al}_{2} \mathrm{O}_{3}$ catalysts are used to investigate their effects on LA production. It is found that surface concentration of Lewis acid sites can enhance the production yield of LA, while that of base sites can affect the amount of HMF. Therefore in the case of mixed catalyst, $\mathrm{ZrO}_{2}$ dispersed on $\mathrm{Al}_{2} \mathrm{O}_{3}$ catalyst can reduce the side reaction of fructose to form HMF. The Lewis acid site is important for converting cellulose into lactic acid, however the balance between Lewis acid and base sites of catalyst should be considered too. The suitable composition between $\mathrm{ZrO}_{2}-$ $\mathrm{Al}_{2} \mathrm{O}_{3}$ for balancing the acid and base sites of catalyst will continue in our investigation to increase the production yield of LA.

This work was supported by Suranaree University of Technology.

\section{References}

[1] Van de Vyver S, Geboers J, Jacobs PA, Sels BF Recent advances in the catalytic conversion of cellulose. Chem Cat Chem 3(1), 2011, 82-94

[2] Yabushita M, Kobayashi H, Fukuoka A Catalytic transformation of cellulose into platform chemicals. Appl Catal B Environ 145, 2014, 1-9

[3] Wee Y, Kim J and Ryu H, Biotechnological production of lactic acid and its recent applications. Food Technol Biotechnol 44, 2006, 163-172

[4] Joglekar HG, Rahman I, Babu S, Kulkarni BD and Joshi A, Comparative assessment of downstream processing options for lactic acid. Sep Purif Technol 52, 2006, 1-17

[5] Lima S, Dias AS, Lin Z, Brand ao P, Ferreira P, Pillinger M, Rocha J, Calvino-Casilda $\mathrm{V}$ and Valente AA, Isomerization of d-glucose to dfructose over metallosilicate solid bases. Appl Catal A 39, 2008, 21-27.

[6] Beatriz Murillo, Arantxa S'anchez, V'1ctor Sebastían, Clara Casado-Coterillo, Oscar de la Iglesia, Mar' 1a P. L ' opez-Ram- de-Viu, Carlos $\mathrm{T}^{\prime}$ ellez, and Joaqu'in Coronas Conversion of glucose to lactic acid derivatives with mesoporous Sn-MCM-41 and microporous titanosilicates, J Chem Technol Biotechnol 89, 2014, 1344-1350.

[7] Yamaguchi, S., Motokura, K., Tanaka, K., and Imamura, S. Catalytic Processes for Utilizing Carbohydrates Derived from Algal Biomass, MDPI catalysts 7, 2017, 163.

[8] Shirai, H., Ikeda, S., and Qian, E.W. One-pot production of 5-hydroxymethylfurfural from 
cellulose using solid acid catalysts, Fuel Processing Technology 159, 2017, 280-286

[9] Yamaguchi, S., Yabushita, M., Kim, M., Hirayama, J., Motokura, K., Fukuoka, A. and Nakajima, K. Catalytic Conversion of BiomassDerived Carbohydrates to Methyl Lactate by Acid-Base Bifunctional $\gamma$-A12O3 (in press).

[10] Wattanapaphawong, P., Reubroycharoen, R and Yamaguchi, A. Conversion of cellulose into lactic acid using zirconium oxide catalysts 7 , 2017, 18561-18568.

[11] Yamaguchi, A., N. Hiyoshi, O. Sato, K. K. Bando

And M. Shirai, ChemSusChem 3, 2010, 737741.

[12] Yamaguchi, A., Sato, O., Mimura, N., Hirosaki, Y.,

Kobayashi, H., Fukuoka, A., and Shirai, M., Catal. Commun. 54, 2014, 22-26.

[13] K. Tomishige, Y. Ikeda, T. Sakaihori and K.Fujimoto, J. Catal., 2000, 192, 355-362.

[14] M. E. Manr'iquez, T. L'opez, R. G'omez and J. Navarrete, J. Mol. Catal. A: Chem., 2004, 220, 229-237.

[15] M. Watanabe, Y. Aizawa, T. Iida, R. Nishimura and H. Inomata, Appl. Catal., A, 2005, 295, $150-156$.

[16] Jin, F., Z. Zhou, Enomoto, H., Moriya,T., and Higashijima, H., Chem. Lett. 33, 2004, 126127.

[17] Kabyemela, B.M., T. Adschiri, R. M. Malaluan and K. Arai, Ind. Eng. Chem. Res. 38, 1999, 2888-2895.

[18] Hayashi, Y.; Sasaki, Y. Tin-catalyzed conversion of trioses to alkyl lactates in alcohol solution. Chem. Commun. 2005, 2716-2718.

[19] Taarning, E.; Saravanamurugan, S.; Holm, M. S.; Xiong, J.; West, R. M.; Christensen, C. H. Zeolite-Catalyzed Isomerization of Triose Sugars. ChemSusChem 2 (7), 2009, 625-627.

[20] Pescarmona, P. P.; Janssen, K. P. F.; Delaet, C.; Stroobants, C.; Houthoofd, K.; Philippaerts, A.; De Jonghe, C.; Paul, J. S.; Jacobs, P. A.; Sels, B. F. Zeolite-catalysed conversion of C3 sugars to alkyl lactates. Green Chem. 12, 2010, 1083-1089.

[21] West, R. M.; Holm, M. S.; Saravanamurugan, S.; Xiong, J.; Beversdorf, Z.; Taarning, E.; Christensen, C. H. Zeolite H-USY for the production of lactic acid and methyl lactate from C3-sugars. J. Catal. 269 (1), 2010, $122-130$.

[22] Li, L.; Stroobants, C.; Lin, K.; Jacobs, P. A.; Sels, B. F.; Pescarmona, P. P. Selective conversion of trioses to lactates over Lewis acid heterogeneous catalysts. Green Chem. 13, 2011, 1175-1181.

[23] Yang,L., J. Su, S. Carl, J. G. Lynam, X. Yang and H. Lin, Appl. Catal., B 162, 2015, 149-157.

[24] Yang, L., X. Yang, E. Tian and H. Lin, ChemSusChem, 9, 2016, 36-41.
[25] Yang, L.,X. Yang, E. Tian, V. Vattipalli, W. Fan and H. Lin, J. Catal. 333,2016, 207-216.

[26] Hisakazu S.; Saki I.;, Eika W. Q., One-pot production of 5-hydroxymethylfurfural from cellulose using solid acid catalysts, Fuel Processing Technology, 2017,159,280-286. 